\title{
Don’t give up your day job
}

\author{
Rob Poole
}

My area of achievement outside of work is no secret. It's my sole topic of conversation. Medical students go glassy-eyed as I attempt to engage them on such non-curricular subjects as 'Is hip hop music? Or not?' Our purchaser has a picture of me clutching my battered Telecaster on his wall. The humiliating fact is everybody knows that I have been reduced to scratching a living as a psychiatrist in order to fund my less lucrative career in music.

As a fan I am quite distinguished, having seen both Simon Rattle and the Sex Pistols before they were famous (sadly on separate occasions). But I am not content to listen. These last 25 years I have played in bands, from punk to country and western, but mostly R'n'B. My natural habitat is the pub gig, that sleazy world of bar fights and loud discordant music. Friday nights you can see my other self, Robbie (gtr, vcls, kybds, harp), in biker's jacket and torn jeans, on stage with an emphatically second division blues band.

Over the years I have worried about the marked mediocrity of every band I've been associated with. I have wondered if a factor other than coincidence is at play. It's not that I lack aspirations. Alone in the early hours I sit at my piano imagining that my compositions occupy the unexplored ground between Dr John and Thelonious Monk. It is the rest of the band who, although experienced (i.e. elderly), seem incapable of making the leap from the flattened third (blues) to the flattened fifth (jazz). Have I compromised my success by excessive diversification? Does it matter that my talent is unencumbered by any noticeable sense of rhythm? With some relief I have eventually realised that the whole point is to not succeed. By remaining at the grass roots one can savour the musical life without being spoilt by the traditional trappings of success (money, drugs, women, early death).

Like parenthood, being in a band is an obligation without a rationale. Also like parenthood, it can take you to transcendant heights, but more frequently takes you to horrific lows. I cherish the moment when the Wang Dangs hit their glorious peak in Bury Knowle Park in Oxford in 1988, for once all 13 of us playing well and John Peel looking on, seeming to enjoy it (until his son vomited and he left). I have to confess that Fat $\mathrm{Al}$ one wet Wednesday night in Warrington three years ago was more typical (two men and a dog in the audience; this time the dog left). Who could ever forget being booked in error on heavy metal night in Runcorn? After a silent response to the first two songs, the third was greeted by a shout of "fuck off granddad". We spent the rest of the evening planning our escape while trying to play 'Stormy Monday' in the style of Motorhead.

The great thing about gigging bands is that they exist in a state of primitive communism. Equipment and sexual partners are communal property. Choice of repertoire is decided collectively through the exchange of obscenities. The tension between laddish camaraderie and personality conflict is fuelled by substance misuse and musical differences. Marital breakdown is a continuous background noise, possibly dictated by musicians' unquestioning devotion to the band above all else; there was never any doubt of the outcome when my wife foolishly tested my loyalty by going into labour with our first child on band practice night. Technically speaking, no one is meant to care about your day job, but musicians are a vulnerable population, especially on Thursdays (giro day). In recent years I have noticed an increasing interdigitation of my two lives. Drummers, contrary to their stoical image, seem to be particularly prone to nasty afflictions, recently including angina ("let's do a slow one, lads"), panic disorder (two) and Tourette's syndrome. I have been contacted late at night on some of these matters, and I can tell you that Saturday night on call in casualty is preferable.

Unfortunately life in a band can drag you across the line between the bohemian and the frankly criminal. As a person in work and therefore with wheels, the doctor in the band invariably ends up with the PA, the drummer's dog and other hangers-on in the back of the car after gigs. One particular evening I miscalculated on a no-right-turn and was stopped by the police. The cigarette being shared in the back of the car suddenly smelt oddly aromatic, and I remembered that we had borrowed parts of the PA without the owner's consent some months before. My panic was fortunately mistaken for drunkenness, distracting the constables. After passing a breath test I was allowed on my way, shaken by intrusive images of General Medical Council hearings involving stolen mixing desks and the use of mobile premises for the purpose of drug misuse. 
The lasting legacy of these years of artistic endeavour is marked tinnitus and a fruitless research career. Merit award committees have been steadfastly unimpressed by my encyclopaedic knowledge of the Stax/Volt back-catalogue and an ability to play in the key of $E$ flat. Gigs paid in beer before unappreciative audiences have contributed to a worsening weight problem. Far from generating income, music has led to negative equity. Our house is full of musical equipment, mainly broken, although the emotional stability of the household has improved since my abandonment of actual instrument practice some years ago (it didn't seem to make much difference anyway).
It may seem pathetic that a middle-aged, greyhaired, stout psychiatrist still staggers around adopting guitar poses that went out of fashion 20 years ago, but I am not alone. All kinds of unlikely senior clinicians share my vice. Rumour has it that in Manchester there is an entire band of psychiatrists. I will refrain from 'outing' anyone. Personally I have as little use for anonymity as I do for dignity and self-respect. So if you live in the North of England and someone's playing Texas blues in the pub, it may be me. Tonite.

Or if your luck's out, it may be the Mancunians.

Rob Poole, Consultant Psychiatrist, Liverpool 